\title{
Premature Myocardial Infarction: A Rising Threat
}

\author{
Meral Kayikcioglu®, Hasan Selçuk Ozkan®, Burcu Yagmur®
}

Department of Cardiology, Faculty of Medicine, Ege University, Izmir, Turkey

Myocardial infarction mostly presents with atypical signs and symptoms and has different risk factors in young individuals compared to older individuals. These risk factors are often preventable, therefore recognizing them and taking precautions can save these patients from suffering myocardial infarction. Scarcity of studies and lack of guidelines for assessment and management of young MI patients, make it more challenging for these individuals to get accurate medical care, even though MI in this age group is on the rise. Traditional risk factors, such as smoking, hyperlipidemia, hypertension, male sex, obesity, and family history of premature cardiovascular disease, contribute to the risk of myocardial infarction at a young age, but additional non-traditional risk factors, such as substance abuse, thrombophilia, coronary anomalies, immune disease, allergic reactions, and psychological stressors, uniquely contribute to the risk profile of young individuals. This review is aimed to discuss and guide the risk factor assessment for the development of myocardial infarction in young individuals based on current evidence and our $>20$-year of experience in Young Myocardial Infarction Clinic.
The risk of a cardiovascular event increases with age. Myocardial infarction (MI) is rarely expected at younger ages and is accepted as a disease of older ages. However, premature MI is on the rise and is a leading cause of premature death worldwide. A possible reason of this rise may be the increased prevalence of traditional atherosclerotic cardiovascular disease (ASCVD) risk factors, such as hypertension, dyslipidemia, diabetes mellitus (DM), and smoking, among younger age groups. ${ }^{1,2}$ Additional risk factors, such as drug abuse and acquired or inherited causes of hemostatic dysfunction, should not be overlooked. Currently, the coronavirus disease-2019 (COVID-19) pandemic has accelerated the increased numbers of young individuals suffering from $\mathrm{MI}^{3}$

The proportion of MIs in young individuals varies according to the age limit used to define young MI in studies and is generally reported as 5\%-13\%., ${ }^{1,-7}$ The MI incidence for a 10 year follow-up was $12.9,38.2$, and 71.2 per 1000 in males and $2.2,5.2$, and 13.0 per 1000 in females in the age groups of 3034, 35-44, and 45-54 years, respectively, in the Framingham Heart Study. ${ }^{8}$ Young MI prevalence in some countries like Turkey and MENA region is unexpectedly high and constitutes a major health problem..$^{9-14}$ MI prevalence before the age of 50 years is $12 \%$ in Europe in the EUROASPIRE IV study, whereas $19 \%$ in the Turkish arm of the study. ${ }^{11}$ In the same study, the mean age of patients with an acute coronary syndrome (ACS) for the European countries was $62.5 \pm 9.6$ years, whereas $58.6 \pm 10.3$ years for Turkey.

The clinical course, risk factors, and coronary anatomy of MIs that develop at a young age differ from those at older ages. ${ }^{15}$ Young patients with MI usually have a better short-term prognosis than middle-aged and elderly patients. ${ }^{16,17}$ In the TUMAR study in the early 2000s, in-hospital mortality of acute MI was significantly lower in patients aged $<50$ years than in other age groups. ${ }^{10,11,18,19}$ Long-term survival is also considered better in younger patients compared to older patients presenting with MI. However, the 10-year survival of a person with MI at the age of 40 will be considerably shorter than that of those aged 60 years. ${ }^{16}$ Therefore, attending physicians should be aware of the differential characteristics of premature MIs and the need for a more comprehensive approach to these patients. All available evidence highlights the importance of earlier interventions to modify the risk factor profile and lifestyle approaches in those with premature MI. ${ }^{20}$ Moreover, the decrease afforded in the incidence of ACS in the last decades is valid in older populations, not in younger males and females who present with MI. This review is aimed to discuss and assess the risk factors that account for MI development in young individuals based on current evidence and our $>20$-year of experince in young MI Clinic. ${ }^{17}$

Corresponding author: Meral Kayikcioglu, Department of Cardiology, Faculty of Medicine, Ege University, Izmir, Turkey

e-mail: meral.kayikcioglu@gmail.com

Received: February 02, 2022 Accepted: February 18, 2022 Available Online Date: March, 14, 2022 • DOI: 10.4274/balkanmedj.galenos.2022-2-19

Available at www.balkanmedicaljournal.org

ORCID iDs of the authors: M.K. 0000-0003-3692-5227; H.S.O. 0000-0001-5282-6179; B.Y. 0000-0002-7120-4698.

Cite this article as:

Kayikcioglu M, Ozkan HS, Yagmur B. Premature Myocardial Infarction: A Rising Threat. Balkan Med J.; 2022; 39(2):83-95.

Copyright@Author(s) - Available online at http://balkanmedicaljournal.org/ 


\section{DEFINITION AND CUT-OFF AGE FOR MYOCARDIAL INFARCTION IN YOUNG INDIVIDUALS}

A universal definition or diagnostic criteria of premature MI is unavailable. Moreover, due to the lack of a consensus for a universally accepted age cut-off for defining young MI, there is a disparity in the literature; some studies vary from $\leq 40$ to $\leq 55$ years of age and others define young MI as $<45$ years of age. ${ }^{21-25}$ Most registries and studies have preferred to use a cut-off age of 4045 years to define "young" patients with coronary artery disease (CAD) or acute MI. However, a stratification approach of these patients by different factors seems more appropriate based on our experience. ${ }^{17}$ These patients can be divided into two groups, as also proposed by the recent literature, ${ }^{1}$ based on the age of the first MI. The classification of patients who had their first heart attack earlier than 40 years of age as 'very young' MI patients, and those who had the first MI between ages 40 and 50 as 'young' MI patients may appear to be rational. This approach may also oversee the important differences with sex, race, and genetics. It's obvious that either very young or young, both age groups require aggressive secondary prevention. . $^{1,26,27}$

Generally, type $1 \mathrm{MI}$, which is caused by atherosclerotic damage and rupture or erosion of a preexisting plaque, is considered when mentioning premature MI. However, understanding that young individuals could suffer from all types of MI is important. Additionally, even with the recent more comprehensive MI definition, it still underestimates other causes of troponin elevation that are unique to younger patients such as autonomic neurocardiogenic syndrome. ${ }^{28}$

\section{RISK FACTORS}

The distribution of etiological risk factors differs in MIs in young individuals than the older ones. The traditional risk factors account for almost $80 \%-85 \%$ of premature MIs, whereas $15 \%-20 \%$ of are due to other factors that trigger thrombosis and/or inflammation, so-called non-atherosclerotic risk factors, ${ }^{20,29}$ which constitute only the $5 \%$ of MIs at older ages. ${ }^{30-32}$ Yang et al. highlighted that patients with very young MI aged $<40$ years are more likely to use both marijuana and cocaine compared to older patients, and patients with young MI between the ages 40 to 50 years are more likely to have traditional risk factors including hypertension, peripheral vascular disease, and higher ASCVD scores. ${ }^{1,4}$ Patients with young MI usually have multiple risk factors, and a cumulative number of these factors significantly increase morbidity and mortality. ${ }^{15}$ Factors that are involved in the etiology should be carefully examined to effectively prevent the re-infarction or further cardiovascular events in patients with young MI. Table 1 and Figure 1 depict the factors that play a role in the development of young MI.

\section{Traditional Atherosclerotic Cardiovascular Disease Risk Factors}

Atherosclerosis is well-known to generate at early ages. The fatty streaks, which could be attributed as the precursors of atheroma, are the cholesterol deposits in the arterial intima and appear in very early childhood. A postmortem study revealed that $20 \%$ of males and $8 \%$ of females have atherosclerotic CAD at the mean age of 30-34 years. ${ }^{33}$ Whereas, the prevalence of CAD was $50 \%$ in cardiac donors with a mean age of 30-33 years as detected by intravascular ultrasound. ${ }^{34}$ In the same study, coronary atherosclerotic lesions were observed in one in six teenage patients. Consequently, the immense presence of atherosclerotic risk factors since early childhood may expose to premature atherosclerosis, thereby leading to early MIs. Therefore, early detection and effective treatment of high-risk young individuals are extremely important for the prevention of early MIs and premature mortality.

One of the earliest studies regarding ASCVD risk factors in patients with young MI, published in 1987 by Weinberger et al, ${ }^{35}$ presented the most common risk factor for these individuals as smoking with a prevalence of $66 \%$. Among these patients ( $\leq 30$ years of age), $56 \%$ reported a smoking history of 20 or more cigarettes per day and only $10 \%$ were smoking $<10$ cigarettes per day. There is no doubt that smoking is the most common and modifiable risk factor in young MIs. ${ }^{27}$ Smoking is reported in $65 \%-92 \%$ of young patients with MI and 24\%-56\% in older patients with MI. ${ }^{6,15}$

Cardiometabolic factors, including obesity, DM, and dyslipidemias, could trigger or promote the development of MI at early ages. Hypertension and DM are less common in young patients with MI than those at older ages, in whom the most common risk factor for $\mathrm{MI}$ is hypertension by far. ${ }^{36,37} \mathrm{DM}$ has been present in only 3\%$5 \%$ of patients with MI aged $<45$ years. ${ }^{38}$ However, patients with MI at younger ages frequently have subtle problems of glucose metabolism. A study of 108 patients without overt DM who had young MI before the age of 45 years revealed that impaired glucose response to oral glucose challenge was present in $65 \%{ }^{39}$

Being overweight or obese is significantly more common in younger patients with ASCVD than in older patients. The Framingham experience has denoted that obesity in middle-aged individuals could account for $15 \%$ of CAD cases in females and

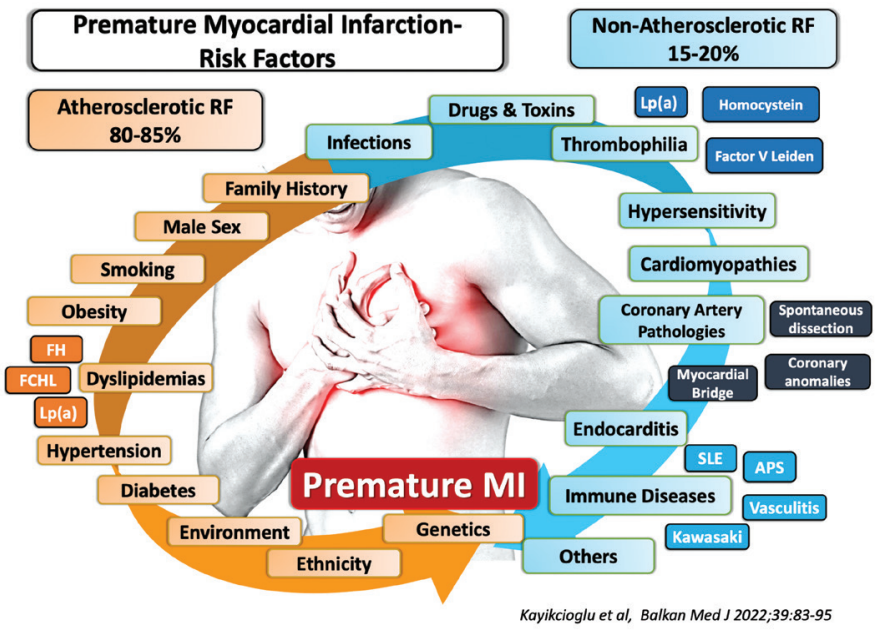

FIG. 1. Risk factors associated with premature myocardial infarction APS, antiphospholipid antibody syndrome; FCHL, familial combined hyperlipidemia; $F H$, familial hypercholesterolemia; $L p(a)$, lipoprotein (a); MI, myocardial infarction; RF, risk factor; SLE; systemic lupus erythematosus 
TABLE 1. Etiological Factors for the Development of Young Myocardial Infarction

\begin{tabular}{|c|c|}
\hline A. Atherosclerotic factors (frequency $80 \%-85 \%$ ) & B. Non-Atherosclerotic factors (frequency $15 \%-20 \%$ ) \\
\hline Family history of premature ASCVD & $\begin{array}{l}\text { Drugs and toxins } \\
\text { - Substance abuse (amphetamines, cocaine, marijuana, etc.) } \\
\text { - Oral contraceptives } \\
\text { - Anabolic steroids } \\
\text { - Binge drinking } \\
\text { - Antiretrovirals }\end{array}$ \\
\hline $\begin{array}{l}\text { Smoking } \\
\text { Male Sex } \\
\text { Obesity } \\
\text { Diabetes Mellitus } \\
\text { Hypertension }\end{array}$ & $\begin{array}{l}\text { Coronary artery pathologies } \\
\text { - Anomalous coronary arteries, coronary fistulas } \\
\text { - Myocardial bridge } \\
\text { - Spontaneous dissection (Pregnancy, inflammatory diseases, } \\
\text { hyperhomocysteinemia, etc.) }\end{array}$ \\
\hline $\begin{array}{l}\text { Dyslipidemias } \\
\text { Familial Hypercholesterolemia,Familial Combined Hyperlipidemia, } \\
\text { Elevated Lipoprotein (a) } \\
\text { Other ultra-rare genetic dyslipidemias } \\
\text { - Tangier disease (ABCA1 mutations) } \\
\text { - Loss of expression of the scavenger receptor B1 (SR-B1) } \\
\text { - LRP8/ApoER2 variants including single nucleotide polymorphism R952Q }\end{array}$ & $\begin{array}{l}\text { Immune-mediated inflammatory disease } \\
\text { - Connective tissue disorders (SLE, etc) } \\
\text { - Vasculitis (Behçet's disease, Takayasu arteritis, Kawasaki disease, Giant cell } \\
\text { arteritis, etc.) } \\
\text { - Antiphospholipid antibodies }\end{array}$ \\
\hline Ethnicity, Founder effect, Consanguinity & $\begin{array}{l}\text { Allergic reactions and hypersensitivity (Kounis syndrome, Eosinophilic } \\
\text { coronary periarteritis, Eosinophilic granulomatosis with polyangitis, etc.) }\end{array}$ \\
\hline \multirow[t]{5}{*}{ Environmental factors (air pollution, socioeconomic status, etc.) } & Infections (SARS-CoV-2, HIV, Chlamydia, Helicobacter pylori, etc.) \\
\hline & $\begin{array}{l}\text { Thrombophilia } \\
\text { Factor V Leiden, Factor II G20210A, MTHFR mutations, } \\
\text { Hyperhomocysteinemia, } \\
\text { Protein C, Protein S, and Antithrombin-III deficiency; } \\
\text { Protein Z A-13G, G-103A, and G79A Polymorphisms; Platelet glycoprotein VI } \\
\text { 13254C alleles, PAI-1 4G allele, Thrombomodulin G-33A polymorphism, } \\
\text { Factor VII Arg/Gln(353), Factor V (G1691A) }\end{array}$ \\
\hline & $\begin{array}{l}\text { Others } \\
\text { - Patent foramen ovale (paradoxical embolism) } \\
\text { - Radiotherapy, } \\
\text { - Tumors } \\
\text { - Endocarditis } \\
\text { - Cardiomyopathies }\end{array}$ \\
\hline & Other genetic factors \\
\hline & $\begin{array}{l}\text { - Hutchinson-Gilford progeria syndrome (LMNA mutations) } \\
\text { - Fragile arteries (NOTCH1 mutations) } \\
\text { - Generalized arterial calcification of infancy (ENPP1 and ABCC6 mutations) } \\
\text { - Pseudoxanthoma elasticum (ABCC6 mutations) } \\
\text { - Kabuki Syndrome (KMT2D and KDM6A mutations) } \\
\text { - } A C E-D D \text { genotype } \\
\text { - } M E F 2 A \text { mutations including 21-bp and 6-bp deletions, and N263S, P279L, and } \\
\text { - G283D polymorphisms } \\
\text { - } S I R T 1 \text { polymorphisms } \\
\text { - } E L A 2 \text { deletions } \\
\text { - } T N F R S F 1 A \text { polymorphism R92Q } \\
\text { - } N T N 1 \text { variant Arg590Leu }\end{array}$ \\
\hline
\end{tabular}

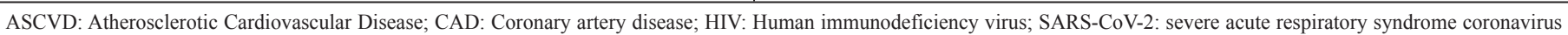

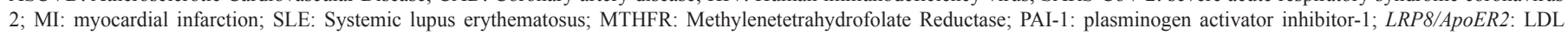

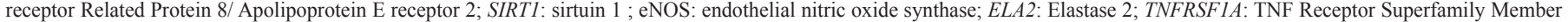

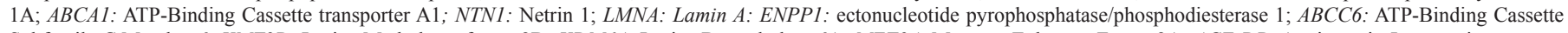

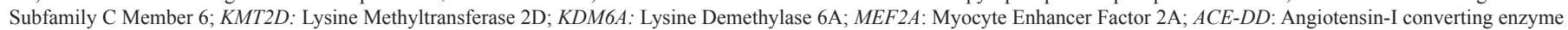
genotype deletion; NOTCH1: Notch homolog 1; translocation-associated 
$23 \%$ in males. ${ }^{37}$ Moreover, obesity is suggested to increase the risk of MI by two to threefold in subjects aged $<45$ years. ${ }^{40}$ However, the current exponential increase of obesity prevalence has been identified as a particular concern for the further increased incidence of young MIs. ${ }^{15,41}$

Primary and secondary dyslipidemias are commonly reported in young patients with CAD. ${ }^{20}$ Increased low-density lipoprotein (LDL) and decreased high-density lipoprotein (HDL) levels have been more frequently detected in individuals with CAD before the age of 40 years compared with those who develop the disease after the age of 60 years ${ }^{42,43}$ Additionally, independent of LDL or HDL levels, elevated triglycerides are consistently identified in patients with early-onset ASCVD. ${ }^{43}$ Patients with young MI have also higher levels of non-HDL-cholesterol. ${ }^{44}$ Goliasch et al. revealed an association of non-HDL-cholesterol with MI in patients aged 40 years depicting an adjusted odds ratio (OR) of 5.02 (95\% confidence interval [CI]: 2.75-9.15) compared to controls adjusted for age, sex and other traditional ASCVD risk factors. ${ }^{44}$

More than half of young patients experiencing MI are reported to have hyperlipidemia. ${ }^{1,2,20,45}$ Inherited hyperlipidemias are also highly prevalent among patients with young MI. Especially familial hypercholesterolemia (FH) and familial combined hyperlipidemia (FCHL) account for an important proportion of premature ASCVD. ${ }^{2,20}$ Wiesbauer et al. reported that approximately $50 \%$ of patients with young MI before the age of 40 years had FH or FCHL. In their young MI population, FCHL alone was associated with a 24 -fold increased adjusted risk (95\% CI: 7.5-81; $P<0.001$ ) for MI. ${ }^{45} \mathrm{FH}$ is an inherited disease of special interest for preventive cardiology within the scope of premature ASCVD, including young MI, as these patients are exposed to high LDLcholesterol levels since their birth unless being started on the lipidlowering therapy at early ages ${ }^{46} \mathrm{FH}$ has been clinically detected in almost $10 \%$ of patients who suffer from MI before the age of 50 years ${ }^{47}$ Patients with premature CAD have a $>15$-fold higher prevalence of FH mutations compared with the healthy controls. ${ }^{48}$ Premature atherosclerosis is extremely common, particularly in patients with homozygous $\mathrm{FH} .^{49}$ Specific mutation-positive $\mathrm{FH}$ patients are more susceptible to premature MI due to more severe coronary lesions compared to mutation-negative individuals. Additionally, polygenic forms of $\mathrm{FH}$ are more common, which might be associated with smaller risk of MI, compared with the monogenic FH. ${ }^{48}$ It's also important to be aware that Dutch Lipid Network Criteria (DLNC) has the highest OR to detect FH in families with premature MI. ${ }^{50}$

Lipoprotein(a) (Lp[a]) is an apolipoprotein (apo)-B containing lipoprotein that is structurally similar to LDL but with an additional plasminogen-like domain that interferes with fibrinolysis. ${ }^{51,52} \mathrm{High}$ $\mathrm{Lp}(\mathrm{a})$ is an established independent risk factor for early ASCVD and aortic sclerosis. Singh et al. reported that one in three patients aged $<50$ years with MI had an $\mathrm{Lp}$ (a) level that exceeds the $80^{\text {th }}$ percentile in the YOUNG-MI cohort. ${ }^{47}$ Patients with premature atherosclerosis and their first-degree relatives have higher levels of Lp(a). ${ }^{53}$ Moreover, children aged $<18$ years, who have premature atherosclerosis in their families, have two to three times higher
Lp(a) levels. ${ }^{54}$ More than $90 \%$ of the levels of $\mathrm{Lp}$ (a) are genetically determined, and the impact of high $\mathrm{Lp}(\mathrm{a})$ levels vary based on the race, with the highest rate in Asian Indians. ${ }^{55}$

Another factor to consider is the family history of premature ASCVD. Family history is reported in a wide range of $14 \%$ to $69 \%$ in patients with young MI in different series. ${ }^{37}$ For example, $40 \%$ of the young patients with CAD have first-degree relatives with premature atherosclerosis. ${ }^{42}$ However, in Weinberg's cohort, the family history of the ischemic disease was positive in only $4 \% .{ }^{35}$ This discrepancy is probably based on the different criteria used to define the family history of premature ASCVD (usually defined as documented ASCVD in a first-degree relative before 55-60 years of age) and the reliability of questioning (recall defect) the family history. ${ }^{16}$ Nevertheless, younger patients with CAD more often have a family history of premature ASCVD compared to those with MI at older ages ( $41 \%$ compared to $28 \%$ in middleaged or $12 \%$ elderly) ${ }^{56}$ Additionally, the offspring of patients with premature CAD are more likely to have traditional ASCVD risk factors than those without such a family history. ${ }^{57}$ These include cardiometabolic risk factors, including obesity, higher lipid levels, insulin resistance, and endothelial dysfunction. ${ }^{58}$ Furthermore, the association between family history and premature atherosclerosis is not only due to genetic factors but also the shared environmental factors. ${ }^{59}$ Environmental factors include lifestyle, air pollution, socioeconomic status, etc. Low socioeconomic status appears to be associated with an increased risk of MI, which may be even more profoundly exhibited in young individuals. ${ }^{60}$

Certain populations due to genetic and environmental factors may have an increased risk of young MI. A very large cohort of patients aged $<40$ years ( $\mathrm{n}=$ approximately 12 million) of databases in the United States revealed that males were predominant, of which a greater portion of individuals was either African American or Hispanic. ${ }^{61}$ Further, the Ashkenazi Jewish population revealed that a Lithuanian mutation, which has been known for $>2$ decades, leads to $\mathrm{FH}$ due to $L D L$ receptor changes, thereby premature CAD. ${ }^{62}$ Additionally, despite the lower prevalence of premature ASCVD in the developed Western World, the increase in South Asia and the MENA region cannot be hindered ${ }^{63,64}$ Noticeably, the high prevalence of consanguineous marriages in the MENA region, India, and Turkey constitute an important underlying cause of MI in young individuals through the increased prevalence of inherited rare dyslipidemias such as FH, FCHL, etc.

There is a large gender bias with most early MIs occurring in males. Male gender is particularly a strong risk factor for ASCVD in young individuals. Therefore, some researchers prefer to define young age as 5-10 years older for females than they define for males in ASCVD. Chan et al. reported that $90 \%$ of patients who suffer from MI aged $<45$ years were males compared to $68.4 \%$ (OR: 3.59 ; 95\% CI: 2.37-5.44) of older patients. ${ }^{65}$ Females constitute only $5 \%-15 \%$ of young patients with CAD compared with $40 \%-50 \%$ in older populations and overall, this proportion among the young MI is suggested to be growing with the increasing proportion of cardiometabolic risk factors and smoking in young females. 35,66 Several hormonal conditions, such as pregnancy and polycystic 
ovary disease, increase the risk of young MI in females. Other hormonal pathologies, including congenital adrenal hyperplasia, Cushing's syndrome, and other androgen synthesizing tumors, may predispose to young MI in both males and females via elevated endogenous dehydroepiandrosterone sulfate (DHEA-S) levels. Excessive DHEA-S is an independent risk factor for premature MI but not for MI in individuals of $\geq 50$ years of age. ${ }^{67}$

\section{Non-Traditional Modifiable Risk Factors}

A variety of non-atherosclerotic risk factors have been identified as promoters and/or contributors in young patients with MI (Table 1, Figure 1). These factors should be evaluated in all patients with MI under the age of 40 years. The younger the age of a patient with premature MI, the higher the possibility of the contribution of nonatherosclerotic risk factors.

Drugs and toxins: Obtaining a detailed drug history is paramount in younger patients with MI. Illicit drug use, particularly cocaine abuse, should be kept in mind in patients with young MI. Amphetamines trigger acute MI through increased sympathetic activity leading to coronary vasospasm and hypercoagulability. Cocaine induces these effects by blocking the presynaptic noradrenaline receptor uptake. ${ }^{2}$ Moreover, long-term cocaine use accelerates atherosclerosis by interrupting the endothelial functions and increasing the cholesterol penetration to the intima. ${ }^{68}$ Smoking marijuana may rarely trigger MI. A study of substance abuse in the YOUNG MI registry cohort revealed a $10.7 \%$ cocaine or marijuana use, which was significantly associated with long-term ASCVD and all-cause mortality. ${ }^{68}$ Binge drinking may also be associated with MI and arrhythmias.

Physically active individuals, without an underlying medical condition, who use anabolic steroids or protein supplements may also have early MI. ${ }^{69}$ Additionally, the use of oral contraceptives, even in low doses, may cause early MI, in females without other predisposing factors. ${ }^{70}$

Coronary Artery Pathologies: Coronary artery pathologies, including coronary congenital anomalies, aberrant anatomy of coronary arteries including fistulas, myocardial bridge, and spontaneous coronary artery dissection (SCAD), constitute important causes of MIs in the young population. Congenital CAD has been suggested to cause sudden cardiac death $(5 \%-35 \%)$ in young individuals. ${ }^{71}$ Abnormal coronary origin is an example of congenital CAD as a possible cause of young MI. ${ }^{71}$ Aberrant course of a coronary artery between the aorta and pulmonary artery may lead to severe ischemia by narrowing the luminal diameter. An enlarged pulmonary artery in patients with severe pulmonary hypertension may also be a cause of young MI. Thrombophilia, either inherited or acquired, and hormone therapy could increase the risk of MI even in non-significant coronary abnormalities.

SCAD is a rare cause of $\mathrm{MI}$ in young individuals, particularly in females aged $\leq 40-50$ years without other predisposing factors. One-third of all cases of pregnancy-associated MIs are related to SCAD. ${ }^{72}$ However, SCAD is not a phenomenon reserved for pregnant women, which may be the cause of MI even in unexpected individuals such as professional athletes at a young age. Moreover, connective tissue disorders (i.e., Ehlers-Danlos syndrome and Marfan syndrome), ${ }^{72}$ hormones, and systemic inflammatory diseases, such as Kawasaki disease and systemic lupus erythematosus (SLE) could be associated with SCAD. Of note, in more than half of the cases with SCAD leading to a MI, there are precipitating factors or events, i.e., intense exercise, emotional stress, cocaine, and vomiting etc. SCAD leads to a hematoma in the outer layers of the coronary arteries, creating a false lumen, which causes ischemia by compressing the true lumen. Mild atherosclerosis is also suggested to cause SCAD. Furthermore, SCAD is associated with fibromuscular dysplasia in $>50 \%$ of cases. ${ }^{6}$

Myocardial bridging (MB) is a developmental anomaly of the coronary artery, usually the left anterior descending, anatomically passing through the myocardium, and mostly detected incidentally. Coronary compression during each systolic contraction may result in delayed opening during diastole leading to ischemia. ${ }^{73} \mathrm{MB}$ may be associated with coronary vasospasm. Moreover, systolic compression may trigger coronary atherosclerosis by causing endothelial injury. ${ }^{73} \mathrm{MB}$ is a rare cause of $\mathrm{MI}$ in general; however, its prevalence is relatively high in patients with young MI. A study that included 884 patients between the ages of 18 and 30 years with chest pain revealed that the most common coronary artery anomaly was $\mathrm{MB}$ with $17.3 \%$ compared with $\mathrm{CAD}$, which was only detected in $4.3 \% .{ }^{74,38}$ Detecting $\mathrm{MB}$ in patients with chest pain is important as it may cause life-threatening arrhythmias even in the lack of apparent thrombo-embolism or atherosclerotic plaques

Immune-mediated Inflammatory Disease: Immune-mediated inflammatory diseases including connective tissue disorders and vasculitis can cause non-atherosclerotic MI in young individuals. Connective tissue disorders cause myocardial damage by several mechanisms such as a coronary artery or aortic dissection, coronary artery aneurysm formation, and thrombus formation. Granulomatous vasculitis, such as Takayasu's disease or Giant cell arteritis (Temporal arteritis), can affect the coronaries and result in MI. Takayasu's arteritis involves the major branches of the aorta and pulmonary arteries and rarely coronary arteries. Takayasu's disease usually affects the coronary ostia ${ }^{75}$ and may present as an isolated coronary lesion in $<5 \%$ of patients. Giant cell arteritis mainly affects large- and medium-sized vessels, most commonly temporal and vertebral arteries. Atherosclerosis may coexist with Giant cell arteritis and usually favors the anterior component of the polygon of Willis and the carotid system. Coronary involvement is rare but may ensue MI. Behçet's Disease may rarely affect the coronary arteries but should be questioned in all patients with young MI, particularly in males. Patients with immune-mediated inflammatory diseases are also prone to accelerated atherosclerosis.

Kawasaki Disease, which is a disease of children aged $<5$ years, can affect the coronaries leading to coronary aneurysm formation and/or dissection in children and young adults. ${ }^{76}$ Post-Kawasaki disease patients are known to have triggered early atherosclerosis and have a higher MI risk probably due to vascular sequela. ${ }^{20}$ 
The autoimmune disorders, particularly the presence of antiphospholipid antibodies (APLA), can cause ACSs via increased coagulability. APLA can develop either alone or in conjunction with other immune disorders, such as SLE. Patients with SLE should always be considered as potential premature MI candidates, not only because they have the most common predominating rheumatic condition among the premature MI cohorts, ${ }^{77}$ but because premature MI can be the first sign of SLE. Patients with SLE harbor a fivefold increased risk of ASCVD, even without APLA. ${ }^{78}$ Immune complexes and complement activation in SLE enhance atherosclerosis initiated by endothelial injury and dysfunction. $^{2}$

Allergic Reactions and Hypersensitivity: Kounis syndrome is a rare cause of coronary artery spasms due to hypersensitivity reaction, which may eventually result in type 2 MI. Drugs and contrast media, such as gadolinium, can result in Kounis syndrome. $^{79}$

Eosinophilic coronary periarteritis (ECPA) is a rare cause of $\mathrm{SCAD}$, which should raise the suspicion in atopic individuals for the risk of premature MI, as the results may be catastrophic. Young patients with ECPA tend to have a history of intermittent vasospastic angina with usually no other accompanying comorbidities. Another cause of eosinophilic tissue infiltration is eosinophilic granulomatosis with polyangitis (EGPA) (formerly known as Churg-Strauss Syndrome) has also the ability to invade the coronary arteries, resulting in granulomatous inflammation, mimicking CAD. The coronary lesions in these patients are usually responsive to immunosuppressive treatment, without a need for revascularization. The known history of EGPA or a previous history of airway hypersensitivity should hinder the recognition of this rare phenomenon. ${ }^{80}$

Infections: Acute and chronic infections increase the risk of MI and atherosclerosis. Acute infections by fever, tachycardia, hypoxia, etc. could lead to a mismatch between the oxygen supply and demand of the heart, leading to myocardial ischemia and acute coronary events. Additionally, chronic infections may account for low-grade chronic inflammation that triggers atherosclerosis. Chlamydia, Mycoplasma, and Helicobacter pylori, which can cause chronic systemic inflammation, are well-documented infectious agents associated with atherosclerosis. Septic vegetations on the aortic or mitral valves may cause MI in case of endocarditis.

Moreover, viral infections may trigger both innate and chronic immune responses and lead to ischemia and MI. Human immunodeficiency virus (HIV), hepatitis C virus, coronaviruses, etc. are important examples of viral infectious agents that are associated with ischemic syndromes. HIV requires special attention since the metabolic effects of the antiretroviral therapy in terms of dyslipidemia can easily be missed and may contribute to the etiology of premature MI. ${ }^{81}$

Currently, the COVID-19 pandemic has also accelerated the increased numbers of young individuals suffering from MI. Severe acute respiratory syndrome coronavirus 2 (SARS-CoV-2) encompasses a variety of cardiovascular syndromes, including pericardial effusion, tamponade, myocarditis, and coronary events. Significant uncertainty remains on the prevalence of acute myocardial injury in patients with COVID-19, which has been reported to cause obstructive or nonobstructive CAD and SCAD. Myocarditis, cytokine storm, and stress cardiomyopathy are the leading considerations, whereas additional potential causes include hypoxemia and microvascular dysfunction from small vessel thrombosis. In cases with COVID-19, fever and tachycardia increase the myocardial oxygen demand, whereas hypoxia decreases oxygen delivery to the heart, leading to myocardial ischemia. A severe form of coagulopathy may also develop during COVID-19 due to the following possible mechanisms: 1) hyperimmune response resulting from cytokine storm, 2) direct endothelial damage, 3) deep hypoxia, and/or 4) continuous prone position. However, the major pathology includes the uncontrolled hyperimmune reaction. There are too many cases of young COVID-19 patients presenting with $\mathrm{MI}$ and even further chronic damage to the cardiovascular system by SARS-CoV-2 is highly suspected as the infection presents itself with endothelial dysfunction and is known to lead to thromboses. ${ }^{82}$ We still do not know whether the history of contracting COVID-19 will be a predictor of ASCVD in the future. Moreover, we still don't know if the children who developed multisystem inflammatory syndrome (MIS) due to COVID-19 would be prone to ASCVD in early adulthood.

Thrombophilia: Thrombophilia either acquired or inherited, approximately accounts for $5 \%$ of all MIs in young patients. ${ }^{20}$ The lower the age of patients with young MI, the higher the possibility of an underlying thrombophilia. Several genetic mutations that disrupt the balance between coagulation and fibrinolysis are well-known associates of $\mathrm{MI}$ in young individuals. ${ }^{29,30,32,52}$ Thrombophilias also harbor the risk of ventricular thrombi in the course of young MI. Thrombophilia predispose to increased risk of thromboembolic events, particularly in the coexistence of acquired or inherited disorders of the hemostatic system/triggering factors, such as pregnancy, ${ }^{32}$ arthropod bite, ${ }^{30}$ and heavy smoking. Prothrombotic mutations in combination with cigarette smoking increase the risk of MI by 12 -fold in young females. Similarly, oral contraceptive agents have been associated with increased risk of MI, especially in smoking females; however, the risk appears low with newer agents.

Factor V Leiden and Factor II G20210A allelic variants are known to cause early MI, especially in young individuals aged $<35$ years. Resistance to activated protein $\mathrm{C}$ (APCR) or acquired deficiency of protein $\mathrm{C}$ are also among the well-known causes of young MI. ${ }^{83}$ Polymorphisms of other coagulation factors may also have important roles in the prognosis and etiology of premature MI. Moreover, fibrinogen and homocysteine (Hcy) levels are accepted as intermediate risk factors that potentiate the effect of the underlying genetic causes. . $^{29,30,32,52,84}$

Factor V Leiden is inactivated ten times slower than the normal factor $\mathrm{V}$, leading to a hypercoagulable state (APCR). ${ }^{31}$ The risk of venous thrombosis is increased 3-5 times in heterozygotes and 50-80 times in homozygotes. Factor V Leiden mutation is the 
most common inherited thrombophilia in certain populations with a prevalence of $5 \%-10 \%$ in Caucasians, which is significantly higher than African and Asian. ${ }^{85}$ It's suggested that this mutation has arisen from Anatolia with a prevalence of $7 \%-8 \%$ in the Turkish population. ${ }^{86}$ APCR could be acquired in pregnancy or with hormone therapy and APLA syndrome.

Prothrombin G20210A gene mutation, which leads to increased prothrombin activity, is present in $1 \%-6 \%$ of Caucasians and was demonstrated to be more common in patients with premature CAD $(2.7 \%-5.1 \%) .{ }^{30}$ The prevalence of this mutation in Turkish subjects is $2.2 \%-2.7 \%{ }^{86}$ With other inherited or acquired risk factors, venous thrombosis is $2-3$ times more frequent.

Antithrombin-III deficiency, which is a rare cause of MI, can be inherited or acquired due to a variety of diseases including disseminated intravascular coagulation, nephrotic syndrome, or renal failure. ${ }^{2}$ Antithrombin-III deficiency mainly increases the risk of venous thrombosis with a relative risk of 8 but may increase up to 20 -fold when other acquired risk factors are co-existing.

Inherited protein $\mathrm{C}$ and $\mathrm{S}$ deficiency can cause severe thrombotic events at early ages. Both could be acquired due to hepatic diseases, warfarin use, inflammatory conditions, pregnancy, and hormone therapy. ${ }^{2}$ Venous thrombosis is increased by approximately $10-$ fold in the heterozygote individuals. Arterial thrombosis is rare but significant thrombotic events usually develop in early ages in inherited forms.

Hyperhomocysteinemia is an independent risk factor for ASCVD. Up to $40 \%$ of patients with premature CAD, peripheral vascular disease, or recurrent venous thrombosis are detected to have elevated Hcy levels. ${ }^{2}$ High Hcy levels cause premature atherosclerosis mainly via endothelial dysfunction and apoptosis of the endothelial and smooth muscle cells. Apoptosis of the smooth muscle cells disturbs the collagen synthesis, which causes plaque instability and increased thrombosis. ${ }^{87}$ Hyperhomocysteinemia impairs the endothelial nitric oxide (eNO)-dependent vasodilation leading to decreased bioavailability of NO but preserving the expression of endothelium-derived nitric oxide synthase (eNOS). ${ }^{2}$ The mutations in the genes that encode the four enzymes involved in Hcy catabolism, including cystathionin $ß$-synthase, methionine synthase, 5,10-methylenetetrahydrofolate reductase (MTHFR), and betaine-homocysteine methyltransferase and the deficiencies of their cofactors (vitamin B6, B12, and folic acid) lead to hyperhomocysteinemia. A meta-analysis depicted a relative risk of 1.05 (95\% CI, 0.86-1.27) for MI and 1.46 (95\% CI, 1.191.79) for ischemic cerebrovascular accident when there was a mutation in the $M T H F R$ gene. ${ }^{88} \mathrm{C}$-to-T substitution at nucleotide 677 within the MTHFR gene, is a relatively frequent missense mutation that is associated with a thermolabile variant and reduced enzyme activity leading to an increased risk of venous thrombosis..$^{30,33,89}$ Patients who are homozygous for the T allele are more likely to have thermolabile MTHFR and elevated Hcy levels compared with other genotypes, and this polymorphism is accepted as a possible genetic risk factor for premature MI. ${ }^{89}$
Other Genetic Causes of Premature Myocardial Infarction: Several gene mutations in lipoprotein metabolism, inflammation, and oxidation may also be associated with young MI (Table 1). Apolipoproteins do not only contribute to the pathophysiology of familial hyperlipidemia syndromes but also have an important association with premature MI. ApoE4/ E4 genotype suggests a strong association with premature MI. Mice with lacking ApoE lose the expression of the scavenger receptor B1 (SR-B1), leading to early CAD. ${ }^{90}$ On the contrary, ApoD has shown cardioprotective properties in experimental atherosclerosis models. ${ }^{91}$ Low levels of ApoCII have been detected in normotriglyceridemic patients with young MI.92 These studies are of utmost importance since some severe forms of these mutations (i.e., frameshift mutations) may result in extreme hyperlipidemias in some families, putting the whole family at risk for premature $\mathrm{MI}$, as seen in $\mathrm{FH}^{93}$

A variant of $L D L$ receptor-related protein 8 (LRP8), which encodes the receptor for Reelin and ApoE-containing ligands, is associated with premature and familial MI. LRP8 variant R952Q results in an increased p38 MAPK stimulation, which leads to increased leukocyte migration and accumulation in the endothelium. ${ }^{94}$ Additionally, LRPS acts as an LDL receptor. Some haplotypes of the LRP8 gene may be protective against familial premature MI. ${ }^{95}$

Tangier disease is a rare but severe inherited condition, resulting in HDL and ApoAI deficiency. Mutations in ATP-Binding Cassette transporter A1 ( $A B C A 1)$ gene lead to cholesterol ester accumulations in tissues resulting in hepatomegaly, splenomegaly, neuropathy, and premature MI. These patients mostly present with yellow-orange tonsils. ${ }^{96}$ In young male patients, $A B C A 1$ polymorphisms can predict the prognosis following MI. ${ }^{97}$

Oxidative stress-related molecules, including eNOS and sirtuin 1 (SIRT1), can also contribute to the pathophysiology of premature MI. In high-risk patients aged $<45$ years, elevated SIRT1 and decreased eNOS levels were associated with premature MI, wherein certain SIRT1 polymorphisms might result in $>2$-fold increased risk. ${ }^{5,98}$

Neutrophil elastase (ELA2) gene deletions, TNFRSF1A gene R92Q polymorphism, which encodes tumor necrosis factor receptor 1 , and the Arg590Leu variant of the netrin-1 (NTN1) gene, which functions in immune cell migration, were depicted as possible inherited causes of premature MI. ${ }^{99}$ Additionally, some molecular deviations result in generalized arterial dysfunction as seen by NOTCH1, ENPP1, or ABCC6 genes. NOTCH1 gene is responsible for transmembrane protein encoding, therefore affording regulatory signals for cell differentiation. Its mutations may result in fragile arteries. The literature already presents a pregnant woman with NOTCH1 mutation, who suffered from premature MI-associated SCAD. ${ }^{100}$ Alterations in genes ENFP1 and ABCC6 cause generalized arterial calcification of infancy and pseudoxanthoma elasticum, respectively. These recessively inherited mutations are characterized by excessive tissue calcifications leading to premature atherosclerosis and severe hypertension. ${ }^{101}$ MEF2A variations can result in autosomal dominant early coronary artery syndromes. ${ }^{102}$ The $A C E-D D$ genotype is associated with premature 
TABLE 2. Baseline Risk Factor Assessment and Diagnostic Algorithm in Patients with Myocardial Infarction at a Young Age (for Females $<50$ Years and Males $<45$ Years)*

\begin{tabular}{|c|c|c|}
\hline & Assessment components & Description and details \\
\hline \multirow[t]{2}{*}{$\begin{array}{l}\text { Detailed Physical } \\
\text { Examination }\end{array}$} & $\begin{array}{l}\text { Additional findings of predisposing factors } \\
\text { of coronary events }\end{array}$ & $\begin{array}{l}\text { - Lipid depositions that could be a clue for FH (arcus cornea, xanthoma, xanthelasma, etc.) } \\
\text { - Any bruits on renal and carotid arteries } \\
\text { - Varicose lower limb veins }\end{array}$ \\
\hline & $\begin{array}{l}\text { Anthropometric measures (weight, height, } \\
\text { waist, and hip measurement) }\end{array}$ & $\begin{array}{l}\text { - BMI of }>25 \mathrm{~kg} / \mathrm{m}^{2} \text { should be an alert for overweight and obesity to be associated with } \\
\text { obstructive sleep apnea }\end{array}$ \\
\hline \multirow[t]{4}{*}{$\begin{array}{l}\text { Screening for } \\
\text { cardiovascular } \\
\text { risk factors }\end{array}$} & $\begin{array}{l}\text { - Hypertension } \\
\text { - Obesity } \\
\text { - Diabetes mellitus }\end{array}$ & $\begin{array}{l}\text { - Systolic BP of } \geq 140 \mathrm{mmHg} \text {, diastolic } \mathrm{BP} \text { of } \geq 90 \mathrm{mmHg} \text {, or a documented diagnosis and/or } \\
\text { treatment of hypertension } \\
\text { - BMI of } \geq 30 \mathrm{~kg} / \mathrm{m}^{2} \text { or a documented diagnosis of obesity } \\
\text { - FBG of }>126 \mathrm{mg} / \mathrm{dl} \text { or random blood glucose of }>200 \mathrm{mg} / \mathrm{dl} \text { or previous diagnoses or } \\
\text { treatment of antidiabetic medications }\end{array}$ \\
\hline & Dyslipidemia & $\begin{array}{l}\text { Total cholesterol of } \geq 200 \mathrm{mg} / \mathrm{dl}, \mathrm{LDL}-\mathrm{cholesterol} \mathrm{of}>130 \mathrm{mg} / \mathrm{dl} \text {, serum triglycerides of } \geq 150 \\
\mathrm{mg} / \mathrm{dL}, \mathrm{HDL} \text {-cholesterol of }<40 \mathrm{mg} / \mathrm{dL} \text { in males or }<50 \mathrm{mg} / \mathrm{dl} \text { in females, or a documented } \\
\text { diagnosis and/or treatment of dyslipidemia }\end{array}$ \\
\hline & Smoking & (Ex/passive, etc.) Daily amount, duration \\
\hline & Alcohol use & Duration, amount \\
\hline \multirow[t]{7}{*}{$\begin{array}{l}\text { History of } \\
\text { ASCVD and } \\
\text { concomitant } \\
\text { disease }\end{array}$} & Any ASCVD & $\begin{array}{l}\text { - Previous MI, stroke, revascularization, SCD, restenosis, heart failure, cardiac devices, and } \\
\text { arrhythmias } \\
\text { - Claudication and peripheral vascular disease } \\
\text { - Transient or permanent vision loss denoting retinal vein or arterial thrombosis } \\
\text { - Erectile dysfunction }\end{array}$ \\
\hline & Other Heart diseases & $\begin{array}{l}\text { - Atrial fibrillation } \\
\text { - Valvular heart disease } \\
\text { - Infective endocarditis } \\
\text { - LV hypertrophy, cardiomyopathies, etc. }\end{array}$ \\
\hline & Infectious disease (Chronic or acute) & $\begin{array}{l}\text { - HIV, chlamydia, tuberculosis, COVID-19, etc. } \\
\text { - Endocarditis, myocarditis (viral illness preceding chest pain and heart failure symptoms) } \\
\text { - Any history of infection during the last few weeks to } 3 \text { months }\end{array}$ \\
\hline & Immune-mediated inflammatory diseases & $\begin{array}{l}\text { - Any connective disease (Ehlers-Danlos syndrome and Marfan syndrome, and fibromuscular } \\
\text { dysplasia) } \\
\text { - Systemic inflammatory diseases or vasculitis (especially SLE, APAS, and Bechet's disease) } \\
\text { - Morning stiffness, arthritis, oral or genital aphthous lesions might be alerting } \\
\text { - Kawasaki disease or similar clinical findings in childhood or adolescence }\end{array}$ \\
\hline & Malignancy, chemotherapy, irradiation, etc. & Previous or active tumors and related treatments \\
\hline & Thrombophilia & $\begin{array}{l}\text { - Any acquired or inherited hypercoagulable state including hyperhomocysteinemia, high } \\
\text { Lp(a) levels, anticardiolipin or antiphospholipid antibodies, inherited thrombogenic mutations, } \\
\text { malignancies, oral contraceptive use, thrombocytosis, erythrocytosis, etc. (see below for } \\
\text { laboratory analysis) } \\
\text { - Hypercoagulable states should be assessed in case of normal coronaries, history of VTE, } \\
\text { history of stillbirth, and missed abortion } \\
\text { - Thrombophilia factors generally coexist and potentialize each other }\end{array}$ \\
\hline & Others & $\begin{array}{l}\text { - Thyroid diseases } \\
\text { - Renal disease and failure } \\
\text { - Hepatic disorders } \\
\text { - Gastrointestinal hemorrhage } \\
\text { - Bleeding diathesis }\end{array}$ \\
\hline \multirow[t]{4}{*}{$\begin{array}{l}\text { Predisposing/ } \\
\text { triggering factors } \\
\text { related to the } \\
\text { index MI }\end{array}$} & $\begin{array}{l}\text { Illicit drug use (cocaine, marijuana, etc.) } \\
\text { Binge drinking }\end{array}$ & $\begin{array}{l}\text { - Patients may be hesitant to report the use of amphetamines or illicit drugs during the initial } \\
\text { visits. Thefore, evaluations for such drugs should be repeated after a few visits } \\
\text { - During the index hospitalization, unexpected tachycardia could be a sign of drug abstinence } \\
\text { - Sweating, dilated pupils, and tachycardia should be an alert for illicit drug use }\end{array}$ \\
\hline & Concomitant medication & $\begin{array}{l}\text { - Anabolic steroids or protein supplements } \\
\text { - Oral contraceptives might increase the risk of premature MI }\end{array}$ \\
\hline & $\begin{array}{l}\text { Heavy sports or activity (football match, } \\
\text { heavy lifting, etc.) }\end{array}$ & $\begin{array}{l}\text { - Heavy sports activity preceding the index event might be a clue for coronary or aortic } \\
\text { dissection }\end{array}$ \\
\hline & Takotsubo Syndrome & - Extraordinary happiness or sadness (broken heart) might be denoting Takotsubo Syndrome \\
\hline
\end{tabular}


TABLE 2. Continued

\begin{tabular}{|c|c|c|}
\hline & Assessment components & Description and details \\
\hline \multirow{4}{*}{$\begin{array}{l}\text { Predisposing/ } \\
\text { triggering } \\
\text { factors related } \\
\text { to the index MI }\end{array}$} & Venous thromboembolism & $\begin{array}{l}\text { - Long-distance flying, lower extremity stasis, etc. could be associated with VTE and patent foramen } \\
\text { ovale }\end{array}$ \\
\hline & Allergy or hypersensitivity & - Kounis syndrome \\
\hline & $\begin{array}{l}\text { Any acute or subacute infection } \\
\text { during the last few weeks to } 3 \\
\text { months }\end{array}$ & - Infective endocarditis and myocarditis \\
\hline & $\begin{array}{l}\text { Information about women cycles, } \\
\text { menstruation } \\
\text { Menopause (age) } \\
\text { Use of Hormones or oral } \\
\text { contraseptives for women }\end{array}$ & $\begin{array}{l}\text { - History of stillbirth and missed abortion might be a clue for thrombophilia } \\
\text { - History of macrosomia may denote diabetes } \\
\text { - Low birth weight children might be associated with placental insufficiency (atherosclerosis) or fetal } \\
\text { hypoxia } \\
\text { - Preeclampsia, hypertension, or diabetes associated with pregnancy } \\
\text { - Polycystic ovarian syndrome (hirsutism and unregular cycles) }\end{array}$ \\
\hline \multirow[t]{5}{*}{ Family history } & Premature ASCVD events & $\begin{array}{l}\text { - MI, revascularization (stent and bypass operation), SCD, heart failure, etc. in first-degree relatives } \\
\text { before the age of } 55-60 \text { years } \\
\text { - How to define family history? } \\
\text { First-degree relative: parents, children, and siblings } \\
\text { Second-degree relative: aunt, uncle, grandpa, grandma, and nephew } \\
\text { Third-degree relative: cousins and grandparents' siblings } \\
\text { - If possible, at least three generations should be questioned }\end{array}$ \\
\hline & Dyslipidemia & $\begin{array}{l}\text { - A detailed family history and lipid profile of all family members should be obtained as possible, and } \\
\text { family screening should be conducted. } \\
\text { - The presence of arcus cornea, xanthoma, and/or xanthelasma should be attributed to FH. }\end{array}$ \\
\hline & Thromboembolic events & - Thromboembolic events in the family may denote inherited hypercoagulable states \\
\hline & Immune disease including vasculitis & - Bechet's disease, SLE, etc. \\
\hline & Other information & - Diabetes mellitus, hypertension, consanguinity \\
\hline $\begin{array}{l}\text { Lifestyle } \\
\text { assessment }\end{array}$ & $\begin{array}{l}\text { Information about healthy lifestyle, } \\
\text { Dietary habits (daily dietary } \\
\text { consumption of fats, carbs, etc) } \\
\text { Environmental factors }\end{array}$ & $\begin{array}{l}\text { - Several questionnaires might be used to obtain data on dietary habits, physical activity, etc. } \\
\text { Dietary Habits and Daily Dietary Consumption Frequency Diagnosis Form } \\
\text { International Physical Activity Questionnaire } \\
\text { - Depression, anxiety, and psychotic disorders are defined as having a documented diagnosis and/or } \\
\text { treatment for these conditions } \\
\text { - Environmental factors include lifestyle, air pollution, socioeconomic status, etc. }\end{array}$ \\
\hline $\begin{array}{l}\text { Psychosocial } \\
\text { evaluation }\end{array}$ & Psychosocial factors & - Social status, marital status, psychosocial issues, etc. \\
\hline \multirow[t]{4}{*}{$\begin{array}{l}\text { Laboratory } \\
\text { analysis }\end{array}$} & Lipid profile & $\begin{array}{l}\text { - Total Cholesterol, LDL-cholesterol, HDL-cholesterol, non-HDL-cholesterol, triglycerides, and } \\
\text { Lipoprotein (a) } \\
\text { - LDL levels of }>155 \mathrm{mg} / \mathrm{dL} \text { in patients with young MI are defined as possible FH according to DLNC }\end{array}$ \\
\hline & Routine biochemistry & $\begin{array}{l}\text { - Analyses include transaminases, creatinine, albumin, uric acid, FBG, HbAlc, electrolytes, TSH, } \\
\text { hemoglobin, and platelet counts. }\end{array}$ \\
\hline & Thrombophilia assessment & $\begin{array}{l}\text { - Blood levels of fibrinogen, homocysteine, B12 vitamin, folic acid, Lp(a), Protein C, S, and ATIII } \\
\text { - Genetic thrombosis panel including Factor V Leiden, Factor V R2, Prothrombin mutation, MTHFR } \\
\text { mutations, and Apo E polymorphism }\end{array}$ \\
\hline & Immune markers & $\begin{array}{l}\text { - CRP, Anti-Nuclear Antibodies, Anti-phospholipid antibodies, Anti-cardiolipin antibodies } \\
\text { - Additional history of morning stiffness, aphthous lesions, arthritis, etc. that might be a clue for } \\
\text { vasculitis or connective tissue disorders }\end{array}$ \\
\hline
\end{tabular}

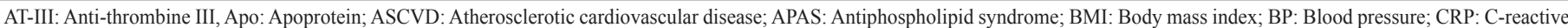

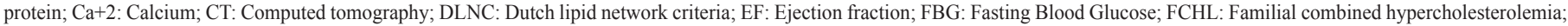

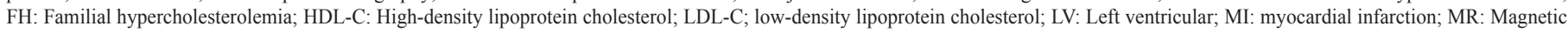

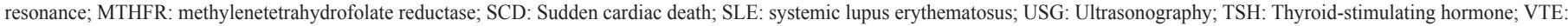
Venous thromboembolism

*The presented information is based on the algorithm established by the Young MI Clinic of Ege University Cardiology Department

MI due to the deletion of both $A C E$ gene alleles, with a 2-fold risk in males compared to females. ${ }^{103}$

Hutchinson-Gilford progeria syndrome is an ultra-rare disease with the autosomal dominant inheritance of $L M N A$ mutations leading to defective lamin A, which is an intermediate filament that normally provides structural support to the cells, leading to structural deformities that mostly affect the smooth muscle cells. These patients mostly die in early decades due to either premature stroke or MI. ${ }^{104}$ Kabuki syndrome, which is associated with intellectual disability and visceral and skeletal abnormalities due to KMT2D and $K D M 6 A$ mutations, may cause premature atherosclerosis and MI. ${ }^{105}$ 
Other Causes of Premature Myocardial Infarction: Other possible causes of MI in young adults should be considered upon initial presentation, as well as irradiation for the treatment of malignant mediastinal disorders, which can lead to intimal damage, medial hypertrophy, and scar formation. Permanent complications rarely develop with a cumulative dose of $<40 \mathrm{~Gy}$.

Coronary embolism and in the presence of patent foramen ovale paradoxical embolism could generate young MI. Paradoxical embolism should be considered in the presence of additional hypercoagulable states (pregnancy, hormone replacement therapy, thrombophilia, etc.) in younger adults with MI. Very rarely, endocarditis, tumors, and immune disorders may cause coronary embolus. Trabeculae of the noncompaction cardiomyopathy may also serve as a source of coronary embolism.

\section{DIAGNOSTIC WORKUP TO IDENTIFY THE UNDERLYING RISK FACTORS}

Table 2 displays our standardized approach to uncover the underlying risk factors in young patients presenting with MI in the Premature MI Clinic of the Ege University Cardiology Department. All patients presenting with MI aged $<45$ years should be carefully evaluated for underlying risk factors for premature atherosclerosis and early MI. For females, the age range might be $<50$ years. The assessment of risk factors for premature MI should be initiated with the diagnosis of MI. Lipid depositions in the physical examination are clues for FH (arcus cornea, xanthoma, xanthelasma, etc.), whereas bruits on renal and/or carotid arteries may denote severe and extensive atherosclerosis, which might be associated with $\mathrm{FH}$ or FCHL.

We use a standard questionnaire covering 6 sections for the evaluation of young patients presenting with MI. We initially focus on the traditional cardiovascular risk factors, i.e., dyslipidemia, hypertension, and DM. If any of these 3 risk factors are present then we ask for the age at diagnosis of each risk factor, the drugs used, efficacy of the treatment (response to treatment), and patients' adherence to therapy.

Secondly, a detailed history of ASCVD and concomitant diseases is collected. History of MI, stroke, revascularization, restenosis, heart failure, cardiac devices, arrhythmias, and claudication are obtained in detail, as well as transient or permanent vision loss denoting retinal vein or arterial thrombosis. Erectile dysfunction should also be questioned in males. Chronic infectious diseases (HIV, chlamydia, and tuberculosis) or acute infections (COVID-19, etc.) might be associated with atherosclerosis or thrombosis. Viral illness preceding chest pain should not be missed in anamnesis. Immune-mediated inflammatory diseases including connective tissue diseases and vasculitis are important in young MI. Symptoms, such as morning stiffness, arthritis, oral or genital aphthous lesions, etc. could be a sign of an underlying immun-mediated disease. The history of Kawasaki disease in childhood should also be considered. Previous or active tumors and related treatments (chemotherapy or irradiation) could be associated with young MI. Thrombophilia evaluation is paramount in those presenting with young MI. Inherited or acquired thrombophilia should be considered in young patients with MI with normal coronaries in the angiogram or history of VTE, history of stillbirth, missed abortions, etc. Furthermore, the presence of permanent or paroxysmal atrial fibrillation, valvular heart disease, and/or infective endocarditis should be kept in mind as rare but possible causes of young MI. Cardiomyopathies, especially those characterized by hypertrophy or metabolic storage diseases may cause young MI either by embolic events or myocardial demand-perfusion mismatch.

Thirdly, we explore the possible predisposing or triggering factors of the index event. Obtaining a careful history of illicit drug use (especially cocaine, rarely marijuana, etc.) is extremely important in patients with young MI. However, patients may be hesitant to report the use of these drugs at initial visits. Therefore, such drug evaluation should be repeated after a few visits. During the index hospitalization, unexpected tachycardia could be a sign of drug abstinence. Heavy sports activity preceding the index event might be a clue for coronary or aortic dissection, meanwhile, extraordinary happiness or sadness (broken heart) might denote Takotsubo Syndrome. Long-distance flying could be associated with venous thromboembolism and patent foramen ovale in patients with young MI. Presence of early menopause, regularity of menstrual cycles, and use of birth control pills or hormone replacement therapy should be evaluated in females. Investigating previous pregnancy-related problems in females is also necessary. Additionally, physical examination findings, such as hirsutism, which may be clues to hormonal disorders, such as polycystic ovary, should be evaluated. Lifestyle assessment and psychosocial evaluation with specific surveys are also important components of the evaluation of young MI patients that will serve for their management (Table 2).

Next, we focus on obtaining a good family history detailed for premature ASCVD events, DM, hypertension, thromboembolic events, immune disease, and dyslipidemia. ASCVD in family history is generally defined as any cardiovascular event in a firstdegree relative before the age of 55-60 years. Meanwhile, we prefer not to limit the family evaluation to the first-degree relatives (i.e., parents, children, or siblings) but also to the second-degree (i.e., aunt, uncle, grandpa, grandma, or nephew) and third-degree relatives (i.e., cousins and grandparents' siblings). If possible, we explore at least three generations for family history. Family history of dyslipidemia is extremely important as FH, FCHL, and high $\mathrm{Lp}(\mathrm{a})$ are frequently inherited contributors of premature atherosclerosis and young MI. Additionally, family members should be assessed for abnormal lipid profiles.

Our laboratory evaluation includes lipid profile (total cholesterol, LDL-cholesterol, HDL-cholesterol, non-HDL-cholesterol, triglycerides, Apo A1 and B, and Lp[a]), laboratory analysis (transaminases, creatinine, urea, uric acid, albumin, fasting blood glucose, electrolytes, thyroid-stimulating hormone, hemoglobin, and platelet counts), thrombosis panel for genetic analysis and immune panel (Table 2). For imaging echocardiography, carotid and vertebral ultrasonography and retinal examination are among the routine workup of patients with young MI. Patients presenting with either acute or subacute MI should undergo 
coronary angiography as early as possible. Any coronary anomaly, plaque erosion, myocardial bridge, SCAD, coronary vasospasm (microvascular dysfunction) and embolism, ectasia, slow flow, and fistulas could be associated with young MI. Younger patients frequently present with single-vessel coronary disease. Multivessel diseases should raise the suspicion of FH, FCHL, HIV, etc. in patients with young MI. Further, $\mathrm{Ca}^{+2}$ scoring is unnecessary in patients presenting with MI. However, healthy relatives may need screening with coronary $\mathrm{Ca}^{+2}$ scoring. Computerized tomographic (CT) angiography could be used in follow-up or especially in females when coronary angiography observes normal or near-normal coronaries. Coronary CT easily captures the coronary plaques with eccentric remodeling and provides information about plaque characterizations either soft or calcified. Plaque morphology also differs between young and advanced age groups. A Chinese optical coherence tomography study revealed that the culprit lesions in patients with acute MI aged $\leq 50$ years had more plaque erosion $(32.0 \%$ vs. $21.1 \%, P$ $<0.001)$ and larger minimal lumen area $\left(2.3 \pm 1.7 \mathrm{~mm}^{2}\right.$ vs. 1.9 $\left.\pm 1.1 \mathrm{~mm}^{2}, P<0.001\right)$ than in those aged $>50$ years. ${ }^{106}$ Plaque vulnerability has inclined from age $\leq 50$ years to $50-70$ years to $>70$ years. Lipid-rich plaque, thin cap fibroatheroma, calcification, spotty calcification, and cholesterol crystals were less frequently observed in young patients. Likewise, multivariate regression analysis depicted that age of $\leq 50$ years was independently associated with less plaque rupture frequency and less vulnerable plaque features.

A recent study further analyzed patients with ACS caused by plaque erosion, ${ }^{107}$ of whom advanced age was associated with higher coronary risk factor prevalence, greater plaque burden, and more vulnerability features. However, predisposing factors, such as FH and other genetic dyslipidemias, may significantly change the plaque morphology. Therefore, an individualized approach would be more appropriate for the treatment of patients with young MI.

In conclusion, the number of younger individuals presenting with MI is steeply increasing and the decrease afforded in the prevalence of ASCVD does not account for young MIs. Individuals with MI at a young age constitute a special patient population with different clinical features compared to patients with older MI. In addition to the traditional risk factors, non-traditional risk factors, such as substance abuse, thrombophilia, coronary anomalies, immune disease, allergic reactions, and psychological stressors, uniquely contribute to the risk profile of young MI. Therefore, patients with young MI should be carefully examined for both traditional and non-atherosclerotic risk factors for effective cardiovascular prevention. However, current guidelines still overlook the cardiovascular risk among patients with young MI, but all available evidence highlights the importance of earlier interventions to modify the unique risk factor profile in premature MI. Therefore, the awareness of the cardiologists on the need for a more comprehensive approach to the distinctive characteristics of premature MIs should be increased. Consensus documents for the management of patients with premature MI are needed.
Author Contributions: Literature Search- M.K., H.S.O., B.Y.; Writing- M.K., H.S.O., B.Y.

Conflict of Interest: No conflict of interest was declared by the authors.

Funding: The authors declared that this study received no financial support.

\section{REFERENCES}

1. Yang J, Biery DW, Singh A, et al. Risk Factors and Outcomes of Very Young Adults Who Experience Myocardial Infarction: The Partners YOUNG-MI Registry. Am J Med. 2020;133:605-612. [CrossRef]

2. Cengel A, Tanindi A. Myocardial infarction in the young. $J$ Postgrad Med. 2009;55:305-313. [CrossRef]

3. Case BC, Abramowitz J, Shea C, et al. Evolution of Management and Outcomes of Patients with Myocardial Injury During the COVID-19 Pandemic. Am J Cardiol. 2021;157:42-47. [CrossRef]

4. Ambroziak M, Niewczas-Wieprzowska K, Maicka A, Budaj A. Younger age of patients with myocardial infarction is associated with a higher number of relatives with a history of premature atherosclerosis. BMC Cardiovasc Disord. 2020;20:410. [CrossRef]

5. Yamac AH, Uysal O, Ismailoglu Z, et al. Premature Myocardial Infarction: Genetic Variations in SIRT1 Affect Disease Susceptibility. Cardiol Res Pract. 2019;2019:8921806. [CrossRef]

6. Gulati R, Behfar A, Narula J, et al. Acute Myocardial Infarction in Young Individuals. Mayo Clin Proc. 2020;95:136-156. [CrossRef]

7. Rallidis LS, Lekakis J, Panagiotakos D, et al. Long-term prognostic factors of young patients. Eur J Cardiovasc Prev Rehabil. 2008;15:567-571. [CrossRef]

8. Kannel WB, Abbott RD. Incidence and prognosis of unrecognized myocardial infarction. An update on the Framingham study. N Engl J Med. 1984;311:1144-1147. [CrossRef]

9. Tokgozoglu L, Kayikcioglu M, Ekinci B. The landscape of preventive cardiology in Turkey: Challenges and successes. Am J Prev Cardiol. 2021;6:100184. [CrossRef]

10. Kotseva K, Wood D, De Backer G, et al. EUROASPIRE III: A survey on the lifestyle, risk factors and use of cardioprotective drug therapies in coronary patients from 22 European countries. Eur J Cardiovasc Prev Rehabil. 2009;16:121-137. [CrossRef]

11. Tokgözoğlu L, Kayıkçığlu M, Altay S, et al. [EUROASPIRE-IV: European Society of Cardiology study of lifestyle, risk factors, and treatment approaches in patients with coronary artery disease: Data from Turkey]. Turk Kardiyol Dern Ars. 2017;45:134144. [CrossRef]

12. Erol MK, Kayıkçığlu M, Kılıçkap M, et al. Treatment delays and in-hospital outcomes in acute myocardial infarction during the COVID-19 pandemic: A nationwide study. Anatol J Cardiol. 2020;24:334-342. [CrossRef]

13. Dugani SB, Murad W, Damilig K, et al. Premature Myocardial Infarction in the Middle East and North Africa: Rationale for the Gulf PREVENT Study. Angiology. 2020;71:17-26. [CrossRef]

14. Setia N, Verma IC, Khan B, Arora A. Premature coronary artery disease and familial hypercholesterolemia: Need for early diagnosis and cascade screening in the Indian population. Cardiol Res Pract. 2012;2012:658526. [CrossRef]

15. Azar RR. Coronary heart disease and myocardial infarction in young men and women. In: Verheugt F, Dardas TF, editors. UpToDate; 2012. [CrossRef]

16. Kayıkçığlu M. How to design studies on premature myocardial infarction? Turk Kardiyol Dern Ars. 2017;45:495-497. [CrossRef]

17. Kayikcioglu M, Kuman Tuncel O, Tokgozoglu L. Impact of the COVID-19 pandemic in patients with a previous history of premature myocardial infarction. Am J Prev Cardiol. 2020;4:100128. [CrossRef]

18. Enar R. Akut miyokard infarktüsü: Trombokardiyoloji. İstanbul: Nobel Tıp Kitabevi; 2004. [CrossRef]

19. Erol MK, Kayıkçıŏlu M, Kılıçkap M, et al. Baseline clinical characteristics and patient profile of the TURKMI registry: Results of a nation-wide acute myocardial infarction registry in Turkey. Anatol J Cardiol. 2020;24:43-53. [CrossRef]

20. Rubin JB, Borden WB. Coronary heart disease in young adults. Curr Atheroscler Rep. 2012;14:140-149. [CrossRef]

21. Abderrahman HA, Al-Abdallat IM, Idhair AK. Age threshold for proper definition of premature coronary artery disease in males. J Forensic Leg Med. 2018;58:45-49. [CrossRef] 
22. Lloyd-Jones DM, Nam BH, D’Agostino RB Sr, et al. Parental cardiovascular disease as a risk factor for cardiovascular disease in middle-aged adults: a prospective study of parents and offspring. JAMA. 2004;291:2204-2211. [CrossRef]

23. Grundy SM, Pasternak R, Greenland P, Smith S, Fuster V. Assessment of cardiovascular risk by use of multiple-risk-factor assessment equations: a statement for healthcare professionals from the American Heart Association and the American College of Cardiology. Circulation. 1999;100:1481-1492. [CrossRef]

24. Nasir K, Michos ED, Rumberger JA, et al. Coronary artery calcification and family history of premature coronary heart disease: Sibling history is more strongly associated than parental history. Circulation. 2004;110:2150-2156. [CrossRef]

25. De Sutter J, De Bacquer D, Kotseva K, et al. Screening of family members of patients with premature coronary heart disease; results from the EUROASPIRE II family survey. Eur Heart J. 2003;24:249-257. [CrossRef]

26. Zhang R, Xie J, Zhou J, et al. Supravalvular Aortic Stenosis and the Risk of Premature Death Among Patients With Homozygous Familial Hypercholesterolemia. Am J Cardiol. 2021;145:58-63. [CrossRef]

27. Shah N, Kelly AM, Cox N, Wong C, Soon K. Myocardial Infarction in the "Young": Risk Factors, Presentation, Management and Prognosis. Heart Lung Circ. 2016;25:955-960. [CrossRef]

28. Y-Hassan S. Autonomic neurocardiogenic syndrome is stonewalled by the universal definition of myocardial infarction. World J Cardiol. 2020;12:231-247. [CrossRef]

29. Rallidis LS, Belesi CI, Manioudaki HS, et al. Myocardial infarction under the age of 36 : prevalence of thrombophilic disorders. Thromb Haemost. 2003;90:272-278. [CrossRef]

30. Kayikçioğlu M, Eroglu Z, Kosova B, et al. Acute myocardial infarction following an arthropod bite: Is hereditary thrombophilia a contributing factor? Blood Coagul Fibrinolysis. 2006;17:581-583. [CrossRef]

31. Kayikçioğlu M, Hasdemir C, Eroğlu Z, et al. Homozygous factor V Leiden mutation in two siblings presenting with acute myocardial infarction: A rare cause of myocardial infarction in the young. Blood Coagul Fibrinolysis. 2005;16:281-286. [CrossRef]

32. Kayıkçıŏlu M, Yavuzgil O, Eroğlu Z, Onay H, Ergenoğlu M, Can L. Hereditary thrombophilia (factor V R2-mutation) as a contributing factor in premature myocardial infarction associated with pregnancy. Anadolu Kardiyol Derg. 2014;14:652-654. [CrossRef]

33. McGill HC, McMahan CA, Zieske AW, et al. Association of Coronary Heart Disease Risk Factors with microscopic qualities of coronary atherosclerosis in youth. Circulation. 2000;102:374-379. [CrossRef]

34. Tuzcu EM, Kapadia SR, Tutar E, et al. High prevalence of coronary atherosclerosis in asymptomatic teenagers and young adults: evidence from intravascular ultrasound. Circulation. 2001;103:2705-2710. [CrossRef]

35. Weinberger I, Rotenberg Z, Fuchs J, Sagy A, Friedmann J, Agmon J. Myocardial infarction in young adults under 30 years: Risk factors and clinical course. Clin Cardiol. 1987;10:9-15. [CrossRef]

36. Zimmerman FH, Cameron A, Fisher LD, Ng G. Myocardial infarction in young adults: angiographic characterization, risk factors and prognosis (Coronary Artery Surgery Study Registry). J Am Coll Cardiol. 1995;26:654-661. [CrossRef]

37. Cole JH, Miller JI 3rd, Sperling LS, Weintraub WS. Long-term follow-up of coronary artery disease presenting in young adults. $J$ Am Coll Cardiol. 2003;41:521-528. [CrossRef]

38. Thompson CS, Pass M, Timothy T, Hung J, Egred M. Acute myocardial infarction in a young elite cyclist: A missed opportunity. BMJ Case Rep. 2019;12:e228560. [CrossRef]

39. Malmberg K, Båvenholm P, Hamsten A. Clinical and biochemical factors associated with prognosis after myocardial infarction at a young age. $\mathrm{J}$ Am Coll Cardiol. 1994;24:592-599. [CrossRef]

40. Hales CM, Fryar CD, Carroll MD, Freedman DS, Ogden CL. Trends in Obesity and Severe Obesity Prevalence in US Youth and Adults by Sex and Age, 2007-2008 to 2015-2016. JAMA. 2018;319:1723-1725. [CrossRef]

41. Wilson PW, D'Agostino RB, Sullivan L, Parise H, Kannel WB. Overweight and obesity as determinants of cardiovascular risk: the Framingham experience. Arch Intern Med. 2002;162:1867-1872. [CrossRef]

42. Chen L, Chester M, Kaski JC. Clinical factors and angiographic features associated with premature coronary artery disease. Chest. 1995;108:364-369. [CrossRef]

43. Breckenridge WC, Little JA, Alaupovic P, et al. Lipoprotein abnormalities associated with a familial deficiency of hepatic lipase. Atherosclerosis. 1982;45:161-179. [CrossRef]
44. Goliasch G, Oravec S, Blessberger H, et al. Relative importance of different lipid risk factors for the development of myocardial infarction at a very young age $(\leq 40$ years of age). Eur J Clin Invest. 2012;42:631-636. [CrossRef]

45. Wiesbauer F, Blessberger H, Azar D, et al. Familial-combined hyperlipidaemia in very young myocardial infarction survivors ( $\leq 40$ years of age). Eur Heart J. 2009;30:1073-1079. [CrossRef]

46. Kayikcioglu M, Tokgozoglu L, Dogan V, et al. What have we learned from Turkish familial hypercholesterolemia registries (A-HIT1 and A-HIT2)? Atherosclerosis. 2018;277:341-346. [CrossRef]

47. Singh A, Collins B, Qamar A, et al. Study of young patients with myocardial infarction: Design and rationale of the YOUNG-MI Registry. Clin Cardiol. 2017;40:955-961. [CrossRef]

48. Pirazzi C, Håkansson L, Gustafsson C, Omerovic E, Wiklund O, Mancina RM. High prevalence of genetic determined familial hypercholesterolemia in premature coronary artery disease. Appl Clin Genet. 2019;12:71-78. [CrossRef]

49. Kayıkçığlu M, Kısmalı E, Can L, Payzin S. Long-term follow-up in patients with homozygous familial hypercholesterolemia; 13-year experience of a university hospital lipid clinic. Turk Kardiyol Dern Ars. 2014;42:599-611. [CrossRef]

50. Beheshti S, Madsen CM, Varbo A, Nordestgaard BG. How to Identify Familial Premature Myocardial Infarction: Comparing Approaches to Identify Familial Hypercholesterolemia. J Clin Endocrinol Metab. 2019;104:2657-2667. [CrossRef]

51. Kayikcioglu M. LDL Apheresis and Lp (a) Apheresis: A Clinician's Perspective. Curr Atheroscler Rep. 2021;23:15. [CrossRef]

52. Kayıkçığlu M, Uzun HG, Tetik Vardarlı A, Tokgözoğlu L. Monozygotic twins with familial hypercholesterolemia and high lipoprotein(a) levels leading to identical cardiovascular outcomes: Case report and review of the literature. Turk Kardiyol Dern Ars. 2020;48:531-538. [CrossRef]

53. Bostom AG, Cupples LA, Jenner JL, et al. Elevated plasma lipoprotein(a) and coronary heart disease in men aged 55 years and younger. A prospective study. JAMA. 1996;276:544-548. [CrossRef]

54. Wilcken DE, Wang XL, Greenwood J, Lynch J. Lipoprotein(a) and apolipoproteins B and A-1 in children and coronary vascular events in their grandparents. J Pediatr. 1993;123:519-526. [CrossRef]

55. Enas EA, Varkey B, Dharmarajan TS, Pare G, Bahl VK. Lipoprotein(a): An underrecognized genetic risk factor for malignant coronary artery disease in young Indians. Indian Heart J. 2019;71:184-198. [CrossRef]

56. Hoit BD, Gilpin EA, Henning H, et al. Myocardial infarction in young patients: An analysis by age subsets. Circulation. 1986;74:712-721. [CrossRef]

57. Bao W, Srinivasan SR, Wattigney WA, Berenson GS. The relation of parental cardiovascular disease to risk factors in children and young adults. The Bogalusa Heart Study. Circulation. 1995;91:365-371. [CrossRef]

58. Gaeta G, Barra D. Anomalie strutturali arteriose nei discendenti di soggetti con infarto precoce del miocardio [Structural arterial abnormalities in the offspring of subjects with premature myocardial infarction]. Recenti Prog Med. 2001;92:136-139. [CrossRef]

59. Topol EJ, McCarthy J, Gabriel S, et al. Single nucleotide polymorphisms in multiple novel thrombospondin genes may be associated with familial premature myocardial infarction. Circulation. 2001;104:2641-2644. [CrossRef]

60. Trzos E, Uznańska B, Rechciński T, Krzemińska-Pakuła M, Bugała M, Kurpesa M. Myocardial infarction in young people. Cardiol J. 2009;16:307-311. [CrossRef]

61. Desai R, Patel U, Parekh T, et al. Nationwide Trends in Prevalent Cardiovascular Risk Factors and Diseases in Young Adults: Differences by Sex and Race and In-Hospital Outcomes. South Med J. 2020;113:311-319. [CrossRef]

62. Meiner V, Landsberger D, Berkman N, et al. A common Lithuanian mutation causing familial hypercholesterolemia in Ashkenazi Jews. Am J Hum Genet. 1991;49:443449. [CrossRef]

63. Ahmed ST, Rehman H, Akeroyd JM, et al. Premature Coronary Heart Disease in South Asians: Burden and Determinants. Curr Atheroscler Rep. 2018;20:6. [CrossRef]

64. Traina MI, Almahmeed W, Edris A, Murat Tuzcu E. Coronary Heart Disease in the Middle East and North Africa: Current Status and Future Goals. Curr Atheroscler Rep. 2017;19:24. [CrossRef]

65. Chan MY, Woo KS, Wong HB, Chia BL, Sutandar A, Tan HC. Antecedent risk factors and their control in young patients with a first myocardial infarction. Singapore Med J. 2006;47:27-30. [CrossRef] 
66. Doughty M, Mehta R, Bruckman D, et al. Acute myocardial infarction in the young -- The University of Michigan experience. Am Heart J. 2002;143:56-62. [CrossRef]

67. Shojaie M, Rajpout MY, Abtahian A, Pour AE, Ghobadifar MA, Akbarzadeh A. Dehydroepiandrosterone sulfate as a risk factor for premature myocardial infarction: A comparative study. Korean J Fam Med. 2015;36:1-9. [CrossRef]

68. DeFilippis EM, Singh A, Divakaran S, et al. Cocaine and Marijuana Use Among Young Adults With Myocardial Infarction. J Am Coll Cardiol. 2018;71:2540-2551. [CrossRef]

69. Jain V, Goel G. Acute myocardial infarction in young newbie bodybuilder using multiple steroid and protein supplements. J Cardiol Cases. 2020;21:134-136. [CrossRef]

70. Rahhal A, Khir F, Adam M, Aljundi A, Mohsen MK, Al-Suwaidi J. Low dose combined oral contraceptives induced thrombotic anterior wall myocardial infarction: A case report. BMC Cardiovasc Disord. 2020;20:182. [CrossRef]

71. Corrado D, Thiene G, Cocco P, Frescura C. Non-atherosclerotic coronary artery disease and sudden death in the young. Br Heart $J .1992 ; 68: 601-607$. [CrossRef]

72. Vrints CJM. Spontaneous coronary artery dissection. Heart. 2010;96:801-808. [CrossRef]

73. Ishikawa Y, Kawawa Y, Kohda E, Shimada K, Ishii T. Significance of the anatomical properties of a myocardial bridge in coronary heart disease. Circ J. 2011;75:15591566. [CrossRef]

74. Burt JR, O'Dell MC, Yacoub B, et al. Prevalence of Abnormal Coronary Findings on Coronary Computed Tomography Angiography among Young Adults Presenting with Chest Pain. J Thorac Imaging. 2021;36:116-121. [CrossRef]

75. Endo M, Tomizawa Y, Nishida H, et al. Angiographic findings and surgical treatments of coronary artery involvement in Takayasu arteritis. J Thorac Cardiovasc Surg. 2003;125:570-577. [CrossRef]

76. Takahashi K, Oharaseki T, Yokouchi Y. Pathogenesis of Kawasaki disease. Clin Exp Immunol. 2011;164 Suppl 1(Suppl 1):20-22. [CrossRef]

77. Krittanawong C, Liu Y, Mahtta D, et al. Non-traditional risk factors and the risk of myocardial infarction in the young in the US population-based cohort. Int $J$ Cardiol Heart Vasc. 2020;30:100634. [CrossRef]

78. Jain D, Halushka MK. Cardiac pathology of systemic lupus erythematosus. J Clin Pathol. 2009;62:584-592. [CrossRef]

79. Abusnina W, Shehata M, Abouzid M, Price M, Zeid F. Kounis syndrome secondary to gadolinium contrast agent. Proc (Bayl Univ Med Cent). 2019;32:253-255. [CrossRef]

80. Chai JT, McGrath S, Lopez B, Dworakowski R. Eosinophilic granulomatosis with polyangiitis (Churg-Strauss syndrome) masquerading as acute ST-elevation myocardial infarction with complete resolution after immunosuppressive therapy: A case report. Eur Heart J Case Rep. 2018;2:yty075. [CrossRef]

81. Gurgo AM, Ferri FM, Iulianella R, et al. Infarto miocardico acuto in paziente HIV-positivo in trattamento con inibitori delle proteasi [Acute myocardial infarct in HIV-positive patients in treatment with protease inhibitors]. Ital Hear J Suppl. 2001;2:1236-1239. [CrossRef]

82. Jin Y, Ji W, Yang H, Chen S, Zhang W, Duan G. Endothelial activation and dysfunction in COVID-19: from basic mechanisms to potential therapeutic approaches. Signal Transduct Target Ther: 2020;5:293. [CrossRef]

83. Samani NJ, Lodwick D, Martin D, Kimber P. Resistance to activated protein C and risk of premature myocardial infarction. Lancet. 1994;344:1709-1710. [CrossRef]

84. Grassi M, Mozzini C, Albertini F, et al. Modeling premature occurrence of acute coronary syndrome with atherogenic and thrombogenic risk factors and gene markers in extended families. J Thromb Haemost. 2005;3:2238-2244. [CrossRef]

85. Rees DC, Cox M, Clegg JB. World distribution of factor V Leiden. Lancet. 1995;346:1133-1144. [CrossRef]

86. Gürgey A, Mesci L. The prevalence of factor V Leiden (1691 G-->A) mutation in Turkey. Turk J Pediatr. 1997;39:313-315. [CrossRef]

87. Zhang C, Cai Y, Adachi MT, et al. Homocysteine Induces Programmed Cell Death in Human Vascular Endothelial Cells through Activation of the Unfolded Protein Response. J Biol Chem. 2001;276:35867-35874. [CrossRef]
88. Kim RJ, Becker RC. Association between factor V Leiden, prothrombin G20210A, and methylenetetrahydrofolate reductase C677T mutations and events of the arterial circulatory system: a meta-analysis of published studies. Am Heart J. 2003;146:948957. [CrossRef]

89. Tomaiuolo R, Bellia C, Caruso A, et al. Prothrombotic gene variants as risk factors of acute myocardial infarction in young women. J Transl Med. 2012;10:235. [CrossRef]

90. Braun A, Trigatti BL, Post MJ, et al. Loss of SR-BI expression leads to the early onset of occlusive atherosclerotic coronary artery disease, spontaneous myocardial infarctions, severe cardiac dysfunction, and premature death in apolipoprotein E-deficient mice. Circ Res. 2002;90:270-276. [CrossRef]

91. Tsukamoto K, Mani DR, Shi J, et al. Identification of apolipoprotein D as a cardioprotective gene using a mouse model of lethal atherosclerotic coronary artery disease. Proc Natl Acad Sci U S A. 2013;110:17023-17028. [CrossRef]

92. Hermans MPJ, Bodde MC, Jukema JW, Schalij MJ, van der Laarse A, Cobbaert CM. Low levels of apolipoprotein-CII in normotriglyceridemic patients with very premature coronary artery disease: Observations from the MISSION! Intervention study. J Clin Lipidol. 2017;11:1407-1414. [CrossRef]

93. Thériault S, Don-Wauchope A, Chong M, Lali R, Morrison KM, Paré G. Frameshift mutation in the APOA5 gene causing hypertriglyceridemia in a Pakistani family: Management and considerations for cardiovascular risk. J Clin Lipidol. 2016;10:12721277. [CrossRef]

94. Shen GQ, Li L, Girelli D, et al. An LRP8 variant is associated with familial and premature coronary artery disease and myocardial infarction. Am J Hum Genet. 2007;81:780-791. [CrossRef]

95. Shen GQ, Girelli D, Li L, et al. Multi-allelic haplotype association identifies novel information different from single-SNP analysis: A new protective haplotype in the LRP8 gene is against familial and early-onset CAD and MI. Gene. 2013;521:78-81. [CrossRef]

96. Puntoni M, Sbrana F, Bigazzi F, Sampietro T. Tangier disease: Epidemiology, pathophysiology, and management. Am J Cardiovasc Drugs. 2012;12:303-311. [CrossRef]

97. Martín M, González P, Reguero JJR, et al. ABCA1 polymorphisms and prognosis after myocardial infarction in young patients. Int J Cardiol. 2006;110:267-268. [CrossRef]

98. Zigra AM, Rallidis LS, Anastasiou G, Merkouri E, Gialeraki A. ENOS gene variants and the risk of premature myocardial infarction. Dis Markers. 2013;34:431-436. [CrossRef]

99. Schönfelder J, Telgmann R, Nicaud V, et al. Neutrophil elastase gene variation and coronary heart disease. Pharmacogenet Genomics. 2007;17:629-637. [CrossRef]

100. Bai B, Zhang M, Zhuang Y, et al. The pregnancy-associated spontaneous coronary artery dissection in a young woman with a novel missense mutation in NOTCH1: A case report. BMC Med Genet. 2020;21:119. [CrossRef]

101. Li Q, Brodsky JL, Conlin LK, et al. Mutations in the ABCC6 gene as a cause of generalized arterial calcification of infancy: Genotypic overlap with pseudoxanthoma elasticum. J Invest Dermatol. 2014;134:658-665. [CrossRef]

102. Wang L, Fan C, Topol SE, Topol EJ, Wang Q. Mutation of MEF2A in an Inherited Disorder with Features of Coronary Artery Disease. Science. 2003;302:1578-1581. [CrossRef]

103. Petrovič D, Bregar D, Gužič-Salobir B, et al. Sex Difference in the Effect of ACE-DD Genotype on the Risk of Premature Myocardial Infarction. Angiology. 2004;55:155158. [CrossRef]

104. Erdos MR, Cabral WA, Tavarez UL, et al. A targeted antisense therapeutic approach for Hutchinson-Gilford progeria syndrome. Nat Med. 2021;27:536-545. [CrossRef]

105. Weir RAP, Alston AF, Ali MA. Acute myocardial infarction in Kabuki syndrome: Chance occurrence or a novel risk factor for premature atherosclerosis? Int J Cardiol. 2014; 176:26-28. [CrossRef]

106. Fang C, Dai J, Zhang S, et al. Culprit lesion morphology in young patients with ST-segment elevated myocardial infarction: A clinical, angiographic and optical coherence tomography study. Atherosclerosis. 2019;289:94-100. [CrossRef]

107. Araki M, Yonetsu T, Kurihara O, et al. Age and Phenotype of Patients With Plaque Erosion. J Am Heart Assoc. 2021;10:e020691. doi:10.1161/JAHA.120.020691. [CrossRef] 